\title{
The Representation of Chineseness in Eat Drink Man Woman
}

\author{
Mengjie Zhou \\ Guangdong University of Foreign Studies, Guangzhou, China
}

\begin{abstract}
Eat Drink Man Woman, well-known as the last episode of "Father-Knows-Best" trilogy directed by Ang Lee, is attractive to numerous scholars following its nomination of Oscar. Through comparative studies, voluminous critics have devoted to the theme of globalization and cultural identity. However, few scholars notice that cultural identity as a sign of national image experiences a series of transformations. Therefore, this article mainly probes how the transformation of cultural identity changes the ideological component of national memory that contributes to nurturing the Chinese national identity. Father's image and daughters' role are prominently represented in the film, particularly father's psychological changes in some sense projecting the transformation of traditional ideology. Thus, combined with historic background this article will set about the transformation of father's role and daughter's image which predicate the deconstruction of traditional gender discourse, trying to figure out how does the transformed ideology expressed through the deconstruction of gender discourse contribute to the reconstruction of Chinese national identity.
\end{abstract}

Index Terms - gender, Chineseness, identity, deconstruction

\section{INTRODUCTION}

Compared with Pushing hands (1991) and The Wedding Banquet (1993), Eat Drink Man Woman (1994) attaches more attention to the collision between tradition and modernity. The collision depicted in the film actually conforms to the historic changeover period of Taipei. The transition of tradition to modernity is a distinct characteristic of Chinese society at the end of $20^{\text {th }}$ century due to the policy of reform and opening up. Eat Drink Man Woman sets the story at Taipei, dealing with a variety of family matters mainly focusing on inter-generational conflicts-between father and daughters. Simultaneously, it narrates the process by which a completely united family is eventually broken as a result of father's remarriage and daughters' getting married. Whitney Dilley once made a comment on the film that "both Pushing Hand and The Wedding Banquet tell a story as to how children let father down, while Eat Drink Man Woman in converse represents how father renders children down" (Dilley, 2015, p. 33). The father in his old age choosing a much younger woman who is his daughter's age as his wife, causes great damage to moral rules, and deteriorates traditional ethic discipline. "Culture is an essential ideological component of national memory that contributes to nurturing national identity" (Edensor, 2002, p. 69). Therefore, the transition of father's image indicates that the traditional moral ideology is to some extent fragmented, which hints the shake of traditional national identity. Besides father's image, females' striving for economic independence, love freedom and gender equality essentially reflects the requirements of the social transition. Conversely, the state during transitional period endows females with more chances to participate in social division of labor, encouraging women to pursue more freedom, rights and independence.

Much of recent scholarship on Eat Drink Man Woman has concentrated on family matters as to the conflict between father and daughters, which can be classified into the purview of ethic and gender issues; on conflict and tolerance between tradition and modernity, male and female, occident and orient, which are apparently represented; and also on cultural identity in the context of globalization. Whitney Dilley, in Globalization and Cultural Identity in the Films of Ang Lee, suggests that "the title Eat Drink Man Woman, which is translated literally from Chinese character "Yin Shi $\mathrm{Nan} \mathrm{Nu}$ ", renders a hybrid feature-the combination of Chinese specific cultural connotation and western language" (Dilley, 2015, p. 118). The hybrid is apparent in globalization process. Also, a few scholars analyze the female images in feminism terms. For instance, compared with WeiWei's relatively weak role in The Wedding Banquet which repeats the motif that female has to hinge on males for a better life, three daughters in Eat Drink Man Woman possess a sense of rebellion due to their courage to pursue love, freedom and independence. From The Wedding Banquet to Eat Drink Man Woman, the patriarchal system is to a large extent weakened. Undeniably, the rise of female groups and their struggling for right, freedom and equality challenge the binary opposition of gender, but few critics notice that this challenge, as a result of the transformation of female's image from conservative to radical, meets the need of social transition.

"In addition to linking female gender with national identity from grand perspective-the transition of society, from the familiar personification of nature-as-female, it is an easy slide to read the nation-as-woman. This depicts "the motherland as spatial, embodied femaleness: the land's fecundity, upon which the people depend, must be protected by defending the nation's boundaries against invasion and violation by foreign males" (Kandiyoti, 1988, p. 285). Another easy slide is that "assigned responsibility for reproducing the group through time, women are singled out as "custodians of cultural particularism" and the symbolic repository of group identity" (ibid: 286). Thus, the above statements provide 
me with justification to interpret the Chineseness in gender terms.

Therefore, this article mainly examines the cinematic representation of Chineseness through the disobedience to traditional gender discourse, and probes how the construction of national identity is related to gender and the medium of film. Through analysis, the conclusion can be made at two levels. Firstly, in terms of the film content, through the deconstruction of traditional gender discourse, females are free from the bondage of domestic area and participate into social works, which satisfies with the requirements of state transition. Secondly, in terms of the form, the disobedience to narrative desire which is based on traditional gender hierarchy, awaking audiences up. This narrative strategy breaks the traditional gender narrative which reduces female's body to the object of male's desire. By reducing the elaboration of female's body and increasing the depiction of how female striving for equality, the film creates a certain contact with the audience, which is conducive to forming an imagined community. Therefore, this article mainly develops analysis from the above two aspects, the deconstruction of gender discourse and the disobedience to narrative desire, which are in terms of film content and form respectively.

\section{GENDER DisCourSE IN ANG LEE’'s FiLM}

"The term discourse used in this article in the sense is defined by Michel Foucault, indicating different ways in which realms of knowledge and social practice are constructed" (Wu, 2010, p. 155). "Discourse is formed by history and society, and embodies a kind of power relation which defines a certain social order and produces individual social status and subject position" (Foucault, 1991, p. 121). Critical analysis of gender discourse examines how social gender is constructed in society and history, and how it becomes an intrinsic part of daily life in the process of which sexual hierarchy and power relations are defined.

\section{A. The Construction of Gender Discourse}

"The core of traditional discourse is the patriarchy. It takes advantages of cultural concepts, institutional arrangements and status identification to uphold man's overbearing position and control of women" (Wu, 2010, p. 156). This traditional discourse is clearly embodied in several films directed by Ang Lee. Such films include Pushing Hands (1991), and The Wedding Banquet (1993). By comparison of two films, it is worth noting that Pushing hands depicts a western female who succumbs to a Chinese male. Gender hierarchy has always been used as a sign of the relationship between occident and orient, the occident personified as "strong" male while the orient as "weak" female, with occident at center whereas orient at marginalized position. However, the question of how to interpret the phenomenon of a western female being controlled by a Chinese male is necessarily discussed. Pushing Hands narrates a traditional story about patriarchy - an American female succumbing to a Chinese male. The Chinese, as a matter of fact, is prohibited to marry American following the announcement of "Chinese Exclusion Law" in 1882. The iron law as an unshakable discourse at that time has determined the unequal relationship between America and China for so long time. It was not until the year of 1943 that the law is canceled. However, the rooted ideology that marriage between Chinese and American is extremely shameful still occupies most western mind even until the end of $20^{\text {th }}$ century. Therefore, in Pushing Hands, an intensive criticism to the binary opposition between occident and orient, and a strong irony to western countries' mistaken imagination on China is produced through a vivid representation of exotic marriage. By situating a weak western female image into the context of the Chinese patriarchal family to discuss, the film unconsciously criticizes the patronizing gaze from occident. Simultaneously, by breaking up the unequal racial relationship, Chinese national image is relatively improved.

However, the removing of stereotype imposed by the west is simply by means of a gender metaphor. The foundation of patriarchal system in Pushing Hands is never shaken. Likewise, The Wedding Banquet upholds and celebrates the legitimacy of the traditional Confucian patriarchal system whereas it validates the underlying homophobic ideology. This homophobic ideology originates from public espousal of traditional gender hierarchy, making heterosexuality become discipline. "In Confucian patriarchy, the discontinuing of a family name due to the lack of an heir is regarded as the biggest offense against filial piety. A man's identity and purpose of existence are not complete until he begets a son"(Dilley, 2015, p. 36). In patriarchal agency governed by Confucian teachings, the existence of women can get their meaning only when they reproduce the patriarchal discourse through the bearing of male children. The Wedding Banquet ends up with all conflicts resolved. Despite the fact that Wei-Tung as the sole son in a traditional family is homosexual, his combination with Weiwei contributes to the continuing of the off-springs, which solids the patriarchal value. In addition, the strengthening of patriarchal dominance relies on the degeneration of female's image. Weiwei' $s$ image is marginalized at two levels. Firstly, she is jobless in America at the risk of being chased away at any time, for she does not get green card. Such a dependent image is set up at the opening scene of the film. Secondly, without regular job and wage, Weiwei attempts to rely on a male to ensure her life. Therefore, the traditional gender discourse is vividly represented in these films.

"According to historical background, the fundamental position of the Chinese government on gender issue has not changed greatly since the reforms started in the 1980s. However, some new contents and forms have been added to the narrative of state discourse. Equality between the sexes has become a basic state policy and woman's equal status has been fully confirmed in official discourse. The Chinese government also enacted the Law of the People's Republic of China on the Protection of Rights and Interests of Women in 1992 and published Development Guidelines for Chinese 
Women in 1995" (Wu, 2010, p. 160).

Given the above contexts, woman's liberation is closely related to national reform and modernization. Based on this background, the fact that most of critics of Eat Drink Man Woman focus on the conflict between tradition and modernity is justifiable. Later, this article will probe how the disobedience to traditional gender discourse represented in the film reflects the social transition.

Pushing Hands and The Wedding Banquet never break up the patriarchal value, but Eat Drink Man Woman makes a great breakthrough in this aspect. Having discussed the national identity through gender narrative, it is of great necessity to make a deep research on this issue on the basis of the text to see how the deconstruction of gender discourse mirrored in the film is related to national identity.

\section{B. The Deconstruction of Gender Discourse}

In Eat Drink Man Woman, the disobedience to the gender discourse is mainly expressed at two levels, the rebellious spirits of females and the crumble patriarchal control.

Females' rebellious spirits can be seen through the performance of Jia-chen. The bickering between Mr.Chu and Jia-chen starts from the use of kitchen, gradually developing into a power struggle between parents and child, man and woman. Jia-chen, a promising cook in her own worlds, is never allowed to step into her father's kitchen, which is clearly represented at the outset of the movie.

While Mr. Chu is preparing for dinner, a pan shot directs the viewer to his kitchen, which is a place full of masculine vigor. "One sees various kinds of knives lining up on the wall, making the kitchen more like a war zone or the practice field of a martial artist than a homey domain. In the following shot, dozens of condiments and herbs settled on the shelves and hung on a string resemble the counter of a pharmacist"(Dilley, 2015, p. 178). There is a certain therapeutic effect in this virile display of power, skill, and professionalism, which "de-feminizes the home kitchen by showing off a father's total control of the space" (ibid, p.179).

Most critics interpret Mr. Chu's tyrannical protection as a manifestation of conventional male bias, for the daughter is not allowed to become a chef, which is a male privilege not only in China but in Europe and America as well. In addition to this prejudice, there is still another level of meaning that needs to be considered: his father envisions that his brilliant second daughter is bound to achieve something higher than simply being a good cook. Given the real situation in China that most of parents hope their children own a promising future, the second interpretation obviously makes sense. However, it is worth noting that Mr. chu's high expectation on his daughter actually reflects the gradually weakened traditional ideology that “a woman without talent is virtuous.”(女子无才便是德). In history, females are not allowed to step out of the domestic area, let alone to join into the affairs of the state. Even during the period from 1949 to 1978 , females still have no chance for schooling due to poverty-stricken situation. For a long time, males are always privileged to acquire educational resources. From Mr. Chu's education concept, there is no difficulty in seeing the fundamental transition of female's social position. Given the background of shooting time, woman's movements in Taiwan benefited from the momentum created during the democratization phase of the early 1990s. They have since become a powerful force, pushing for gender equality measures such as mandatory gender quotas. "Riding on the wave of momentum created by the democratization trend that first started in the late 1980, woman's organizations have been a powerful force behind gender politics in Taiwan" (Clark and Lee, 2000, p. 32). The female roles in Eat Drink Man Woman are to some extent set in accordance with the reality of female situation in the context of social transition.

In the finale of the movie, Jia chen moves back into the old house, returning back to the space of kitchen which is the representative of the patriarchy. Jia chen's rebellious spirit reflects females' resistance to patriarchal control. If Mr. Chu' s educational concept unconsciously appeals to equality between man and woman, Jia chen's aggressive intrusion to father's space which has always been dominated by himself, should become a symbol of taking place of the father. This behavior fundamentally deconstructs the traditional gender discourse to some extent.

In addition to females' image, the male's role also deserves to be noticed. When all three of his daughters work, Mr. Chu is always seen moping around the house: he cooks, cleans, and does laundry for the whole family. These domestic activities render him to take up the role of a feminized housekeeper. Simultaneously, his three daughters are outside the house, joining different work forces. They actively participate in the construction of a new female identity in which the gender boundary between the inside and the outside has been reconfigured in the context of the Taiwan's changing economy.

This collapse of spatial and ideological boundary amounts to an important inquiry into the traditional structure of family unit within which father and mother often embody the opposition between inside and outside, femininity and masculinity. The film adopts a progressive perspective that neutralizes the imperious power of Mr. Chu by transforming him into a housekeeper who diligently performs traditionally woman's labor. It is in this sense that we see the promising trans-sexual aspects of Mr. Chu who is willing to adapt and contribute to the progress of society. His action, in a sense, facilitates women's liberation in and from the house and his ambiguous role as an overbearing patriarch and protective matriarch steers the film towards a deconstruction of conventional gender hierarchy.

Since the twentieth century, emancipating females is one of the goals of the New Culture Movement (around the time of the May $4^{\text {th }}$ Movement in 1919). New intellectuals suggest that females being able to receive education and participate into government affairs are the key to the transition of the state. The transition of the state means 
optimization of social structure from politics, economy to culture, which contributes to the reconstruction of the national identity.

Having discussed the disobedience to gender discourse from both male and female's image, it is of necessity to discuss it from the perspective of traditional Confucianism. The discontinuing of the male heir that discussed in The Wedding Banquet acquires a different interpretation in Eat Drink Man Woman. The latter one well explains that females' strong resolution to take care of parents is no less than males. In Pushing Hands, the representation of filial piety finds its expression in filial accompany with parents. For instance, whether son or daughter, the only child should live with their parents, giving them enough care and accompany, which is the fuse for the bickering between wife and husband in Pushing Hand. In Eat Drink Man Woman, facing the reality that the three daughters will eventually leave him, following the reconstruction of their own family, and being unable to live or stay with him forever, the father has to consider the same question that all Chinese parents must face- filial accompany at their senectitude.

Though with the same motif of filial accompany, the two films have a totally different ending. Pushing Hand ends up with a comedy that the family reunite, while Drink Eat Man Woman witnesses a sad story in which the family is fragmented, two daughters having their own family, one daughter leading her own life without father's company any more. By comparison, it is worth probing the reason why males as an irrevocable bond, are capable of keeping the integrity of a family while females are not. In fact, this question discloses a common phenomenon in China that males as legitimate inheritor, inherit almost all properties from last generation, ranging from estate property to wealth, so they should take responsibility to care for the elderly life of their parents. In contrast, females once getting married, are soon excluded out of the original family scope. Given two different endings, it is worth noting that the reason actually lies in the difference of gender identity. In Pushing Hands, in face of the objection from wife, the son insists on living with father, which is representative of the patriarchal authority. In Eat Drink Man Woman, the real power, however, is grasped by the hands of father. The rooted ideology that daughters are unable to be counted on forces father to choose a woman who's his daughter's age, which reflects Chinese rural rituals about "raising male children can prevent one from loneliness in old age". In Pushing Hand, the son as the male identity is obviously more powerful than the three daughters in Eat Drink Man Woman.

However, the ambiguous identity of Jia Chen enables female image to be more powerful. Firstly, at the opening scene of the film, Jia Chen shows independent female image by means of moving out. This behavior illustrates her inner world that she desires to be an independent woman. Jia-chen, of the three daughters, who most likely leaves her father at last moves back and stays in the old house. Between promising job and old father, Jia chen chooses the latter one without any hesitation. In fact, Jia chen's decision proves that she expects to be like father's son to take care of the elderly life of her father. Therefore, though defined in biological terms, father and Jia chen are male and female respectively, their ambiguous gender identity reflected in the labor division, with father playing mother's role, while daughter playing a son's role, breaks the unbalance in gender.

In the reform movement of 1898 , the function of female's reproduction to the construction of the state is highly stressed. A healthy woman has a strong bearing on the cultivation of next generations, and a brand-new nation mostly depends on the new generation. However, this standpoint serving up for the patriarchal value, defines female value as cultivating the next generation. Females are limited to the household of domestic area. Jill Vickers argues that "patriarchal social relations can be interpreted as one way of constructing enduring forms of social organization, group cohesion and identity" (Vickers, 1990, p. 483). In another word, female's emancipation, deconstructing the patriarchal center, is of great significance to the transformation of the state.

As to the above two viewpoints, a conclusion can be made at two levels. Firstly, female gender is closely related to national identity. Secondly, a positive viewpoint about female is that a large proportion of uneducated female corresponds to a relatively undeveloped nation, while the increasing number of modern and educated females can contribute to building a progressive and civilized national identity.

The above two points can be demonstrated by a comparison of the female images in Zhang Yimou and Ang Lee' s film. In Raise the Red Lantern (1991), one of the most representative films by Zhang Yimou, wins the $64^{\text {th }}$ Oscar. This film sets the story at the republic years of China which is during the period from 1912 to 1949. The film highlights that females' miserable fate is due to a tyrannical control by both patriarchal dominance and conservative feudalism. In this sense, the relation between female and nation is constructed. While Ang Lee's Eat Drink Man Woman, by elaborating the changeable relations between father and daughter, which is a metaphor of relations between man and woman, on the surface focuses on cultural collision and family matters, actually reflecting the background of the traditional society transiting toward modern society. Therefore, the different female images, either civilized or uncivilized, educated or uneducated, represented through the medium of film, can influence thousands of audiences' imagination of China. Teresa Joseph also evinces that gender and nation are identities based on social and historic that construct, playing an important role in the formation of each other as well.

\section{Disobedience To The NARRATIVE Desire}

Having discussed the relation between traditional gender discourse and national identity, it is significant to turn to the relationship between national identity and cinema. "Aesthetically, the main features of the $19^{\text {th }}$ century novel according to Anderson's persuasive account become fundamental in allowing readers to consider themselves as members of 
national community, namely the idea of simultaneity and the chronotope, were both inherited by cinema, through parallel editing and mise-en-scene respectively, and were all the more effective since they did not require literacy to convey meaning" (Gaines, 2003, p.102). The cinema-going experience is a particularly effective way to interpellate an audience in the complex process of identity-construction, including, of course, the construction of national identity. Zhang Yimou's Hero is understood as a film about the representation of the Chineseness. The Chineseness of Hero lies in its embodiment of the philosophy of Tao. The film is interpreted as conveying the message that individual's sacrifice is the ultimate good if it is for the benefit of the larger group, and that loyalty to the national group overrides everything. Likewise, the disobedience to narrative desire which is a narrative strategy based on gender hierarchy in Eat Drink Man Woman, appealing to the equality between man and woman, indicates a prosperous and modern national image.

Discussion of narrative desire and the dynamics of reading pleasure are most often inflected by psychoanalysis, as shown in Peter Brook's Reading for the Plot and Teresa de Lauretis's Alice Doesn 't: Feminism, Semiotics, and Cinema, both published in 1984. As these two texts "continue to inform discussion of desire in narrative, it is fundamental to return to them in order to contextualize my examination of Eat Drink Man Woman" (Brooks, 1984, p.145). For Brooks, narrative desire works at the levels of both story and discourse: "Narrative both tell of desire-typically present some story of desire-and arouse and make use of desire as dynamics of signification" (ibid: 147). Brooks' s theory of narrative desire is founded on gender privilege that takes heterosexual male desire and pleasure as universal, trans-historical, and trans-cultural. In a theory that employs the Freudian model as the foundation for all narrative desire, female narrative desire and subjectivity are always delimited by the masculine Oedipus: "the movement of narrative discourse, which specifies and even produces the masculine position as that of the mythical subject, and the feminine position as mythical obstacle or simply, the space in which that movement occurs" (De Lauretis, 1993, p.143). Female spectators, then are seduced into femininity by identifying with both the masculine subject and the feminine other. Winnett clearly shows how accounts of narrative desire that rely upon gender hierarchies do not adequately account for female narrative desire. This essay presents a reading of Eat Drink Man Woman from a perspective that is different from many of the early academic and popular reviews and readings of the film. The film articulates the kinds of resistance that Winnett "proposes and enacts the proliferation of stories from multiple perspectives"(Winnett, 1990, p.123). The film resists militaristic patriarchal master narratives thematically through the refusal of moving sex directly on the screen. Whitney in "Globalization and Cultural Identity in the Films of Ang Lee" voices that in the two pairs of the four-word idiom, Eat Drink Man Woman, the larger motif of food and sex, the fundamental components of all human life, are implied in a neat short-hand of translated Chinese. The title refers to a popular classical characterization of basic human needs: drink (yin), eat(shi), and sex(nan nv) are irrepressible human desires. This premise highlights the physical and ideological connection between food and desires in the story.

As the film opens, the viewer is treated to the sights and sounds of all manner of traditional Chinese gourmet cooking, which "presumably involves the use of certain tools, cooking techniques, and animal organs not found in the western kitchen. This may provide a shock or at least a pleasurable voyeurism for the western viewer" (Dilley, 2015, p. 197). This voyeurism aroused by the food, is a metaphor of male's desire for female. From opening scene to the end of the film, there are so many close-ups on the food, with the family sitting around the table to conduct weekly communication. In communication of the first five times, the topic almost revolves around daughters' matter, either moving out for independence, or finding their own love one after another. Particularly, in the last family communication that is the sixth time, when Mr.chu declares his love to Jingrong, the news takes everyone aback. Mr.chu' s hidden idea which relates to both sexual desire and passion for a much younger female is simply represented through an implicit way-representing the food, which is human's original desire.

In “Ang Lee's film, female body has always been subject to males' gaze, satisfying voyuerism of the audience. Male as the subject of the gazing while female as the object being gazed, of which the unequal position between man and woman has always been a metaphor of the relationship between the occident and the orient. That is to say, China as the otherness is always gazed by western country. This metaphor relation between gender and national imagination is conducive to breaking up the occidental imagination of China by the disobedience to the narrative desire. Secondly, by reducing to take female's body as a gimmick, the film in narrative terms weakens the gaze from males and avoids the internalization of this gaze among female groups. This awakes the audiences up, forming a new imagined community, which contributes to the embrace of new national identity.

\section{CONCLUSION}

Through a close-reading of Eat Drink Man Woman, this article conducts a detailed study on the relation between gender and national identity from two aspects: the deconstruction of gender discourse and the disobedience to narrative desire. By considering the real situation of China in 1990s, which is also the shooting time of the film, this article contends that the ambiguous gender identity reflected in the film accords with the real situation of the historic background, satisfying the requirements of the social transition. In terms of the narrative strategy, the film breaks the traditional gender narrative. Both in content and form, the film helps to break up the binary opposition of gender, contributing to the interaction with audiences, and therefore forms an imagined community, which is eventually representative of a new Chinese national identity. 


\section{REFERENCES}

[1] Brooks, Peter. (1984). Reading for the Plot: Design and Intention in Narrative. New York: Knopf.

[2] Clark, Cal, and Rose J. Lee. (2000). Democracy and "Softening" Society. Democracy and the Status of Women in East Asia. (Eds). Boulder, CO: Lynne Rienner, 185-192.

[3] Dilley, Whitney. (2015). The Cinema of Ang Lee: the Other Side of the Screen. New York: Wallflower Press.

[4] Edensor, Tim. (2002). National Identity, Popular Culture and Everyday Life. New York: Berg.

[5] Foucault, M. (1991). Nietzche, Genealogy, History. P. Rabinow (Ed.). The Foucault Reader. London: Penguin.

[6] Gaines, J.M. (2000). Dream/Factory. Gledhhill\&L. Williams(Eds). Reinventing Film Studies. London: Arnold.

[7] Kandiyoti, Deniz. (1988). Bargaining with Patriarchy. Gender \& Society, 2(3): 274-290.

[8] Lauretis, Teresa de. (1984). Desire in Narrative. Alice Doesn't: Feminism, Semiotics, Cinema. Bloomington: Indiana UP.

[9] Vickers, Jill McCalla. (1990). At His Mother's Knee: Sex/Gender and the Construction of National Identities. Greta Hoffmann Nemiroff (Ed), Women and Men: Inter-disciplinary Readings on Gender. Toronto: Fitzhenry\&Whiteside.

[10] Winnett, Susan. (1990). Coming Unstrung: Women, Men, Narrative, and Principles of Pleasure. PMLA 105(3):505-18.

[11] Wu Xiaoying. (2010). From State Diminance to Market Orientation: The Composition and Evolution of Gender Discourse. Social Sciences in China, 31(2): 150-164.

Mengjie Zhou is a postgraduate in cultural study of Guangdong University of Foreign Studies. Her research field covers literature and theory. 